\title{
A SIMULATION ANALYSIS OF THE STRENGTH OF AN INNOVATIVE SUPPORTING STRUCTURE OF A MECHANICAL PNEUMATIC SEED DRILL
}

\author{
L. Gierz ${ }^{*}$, J. Selech $^{* *}$, J. Marcinkiewicz ${ }^{* * *}$, D. Ulbrich ${ }^{\dagger}$, D. Romek ${ }^{\ddagger}$, \\ Ż. Staszak ${ }^{\star \star}$ D. Wojcieszak ${ }^{\S}$
}

\begin{abstract}
In order to increase the efficiency of farming machines it is necessary to increase their size. It involves the need to apply new methods optimizing strength parameters to reduce the weight of machines without deterioration of their constructional properties. Therefore, the aim of this study was numerical analysis of an innovative construction of the supporting frame of a mechanical pneumatic seed drill. Data concerning the conditions of operation were used to prepare load characteristics. The data concerning the construction were used to prepare calculation models for the finite element method (FEM). The simulation tests and the analysis of the results provided information about the distribution of tensions in the construction of the supporting frame of the seed drill. The strength analysis is significant due to the new method of assembling the supporting frame of the seed drill.
\end{abstract}

Keywords: supporting frame, seed drill, analysis, FEM

\section{Introduction}

The efficiency of machinery is increasing due to continuous progress. Simultaneously, constructors are forced to design machines with greater working widths or to engineer equipment operating at higher working speeds. When the working width exceeds $3 \mathrm{~m}$, it is necessary to use a foldable frame structure. These solutions can be observed in large combined cultivators and seed drills as well as pneumatic seed drills (Rutkowski \& Szczepaniak, 2005). In order to obtain a high yield of cereals and other crops it is necessary to sow seeds accurately. This procedure requires adequately constructed seed drills.

In order to meet these requirements constructions are constantly being improved and engineers are searching for new constructional solutions to guarantee functionality, durability and strength. Reference publications provide a wide range of methods showing how to check the strength of constructions. For example, there are strength calculations at the stage of designing, tension measurements on real objects as well as simulations based on mathematical modelling (Zastempowski et al., 2014, and Zastempowski et

\footnotetext{
Łukasz Gierz, PhD.: Poznań University of Technology, ul. Piotrowo 3, 60-965Poznan, Poland, Institute of Machines and MotorVehicles (lukasz.gierz@put.poznan.pl)

** Jarosław Selech, PhD.: Poznań University of Technology, ul. Piotrowo 3, 60-965Poznan, Poland, Institute of Machines and Motor Vehicles (jaroslaw.selech@put.poznan.pl)

*** M.Sc., eng.Jacek Marcinkiewicz: Poznań University of Technology, ul. Piotrowo 3, 60-965Poznan, Poland, Institute of Machines and Motor Vehicles (jacek.marcinkiewicz@put.poznan.pl)

$\dagger \quad$ Dariusz Ulbrich, PhD.: Poznań University of Technology, ul. Piotrowo 3, 60-965Poznan, Poland, Institute of Machines and Motor Vehicles (dariusz.ulbrich@put.poznan.pl)

$\$ \quad$ M.Sc., eng. Dawid Romek: Poznań University of Technology, ul. Piotrowo 3, 60-965Poznan, Poland, Institute of Machines and Motor Vehicles (dawid.e.romek@doctorate.put.poznan.pl)

Żaneta Staszak, PhD.: Poznań University of Technology, ul. Piotrowo 3, 60-965Poznan, Poland, Institute of Machines and Motor Vehicles (żaneta.staszak@put.poznan.pl)

$\S$ Assist. Prof.Dawid Wojcieszak, PhD.: Poznan University of Lifesciences, ul. Wojska Polskiego 28 , 60-637 Poznan, Poland, Institute of Biosystems Engineering (dawid.wojcieszak@up.poznan.pl)
} 
al., 2015). Initial simulation of the strength of elements of machinery by means of supporting programs after positive verification of the prototype construction is a method that is gaining popularity because it considerably reduces the costs of production of new farming machinery. The results of simulations testing the strength of farming machinery validated with tension measurements at test facilities or during regular work are highly convergent (Szczepaniak \& Pawłowski, 2005). The finite element method uses the construction model with discrete finite elements (Rutkowski \& Szczepaniak, 2005, and Zienkiewicz et al., 2005). This calculation model ensures a simple and regular geometric shape of the construction under analysis. As earlier initial tests of strength based on one-dimensional finite elements were not precise enough, researchers decided to develop the problem of optimisation of this innovative construction. The aim of this study was numerical analysis of an innovative construction of the supporting frame of a mechanical pneumatic seed drill in the working position. The analysis is based on one-dimensional, twodimensional and gap elements. It will enable optimisation of strength and durability parameters of the construction. The finite element method used for modelling of supporting units enables analysis of the degree of deformation and tension of supporting elements under complex actual loads (Marti, 2013). It is particularly important for engineers searching for new constructional solutions because there are variable constructional parameters at the stage of devising and designing complex units and machinery. It is a priority to identify the distribution of tensions in sets of supporting elements because it enables verification of specific constructional solutions. Numerical analyses are a method of optimising model parameters to find the best solution in terms of weight and supporting functions (Chodurski et al., 2015, Ferdynus, 2013).

\section{Material and research methods}

The research employed the FEM to analyze the strength parameters of the supporting elements of a patented innovative frame of a mechanical pneumatic seed drill during operation (Gierz et al., 2014, and Gierz et al., 2013). The research was conducted on the supporting elements of a mechanical pneumatic seed drill prototype, excluding elements of the steering system and constructional details with no significance to strength. The geometric model of the item under analysis (Fig. 1) was assembled by means of the Autodesk - Inventor Professional 2017 program on the basis of technical documentation of the device. The modeling, discretization and detailed calculations of the strength of the elements of the frame were conducted using the finite element method and the available I-DEAS computing package. Pre- and postprocessors of graphic engineering interpretation were used to describe the calculation model (Fig. 2) with finite elements. The following elements were used in the model:

a) one-dimensional elements:

-beams with twelve degrees of freedom to model the frame structure of the machine,

-rigid elements,

b) two-dimensional elements:

-plate-coating elements to model sheet metal surfaces and closed profiles,

c) gap elements defining contact between elements of the frame.
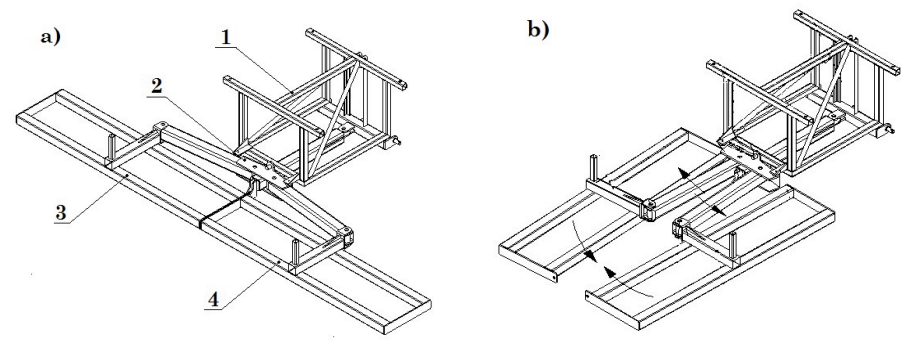

Fig. 1: A geometric model of the supporting frame of a mechanical pneumatic seed drill prototype: 1 central frame, 2 - main frame, 3 - left coulter frame, 4-right coulter frame-a) working position, b) transport position

The model of boundary conditions assumed that the place of frame aggregation was fixed. Therefore, the supporting frame was fixed at the place of aggregation with a tractor, i.e. in a three-point suspension system during transport. At the working position, it was additionally burdened by forces exerted by the coulters. The effect of the coulters on the coulter frames was reduced to the resultant force and moment. The vertical component of the reaction of coulters was assumed so as to make their sum balance the 
weight of the whole machine with filled seed containers. The horizontal component of the ground resistance force was calculated on the basis of Goryachkin's straight theory. The central frame corpus was loaded at four points with the weight of containers filled with seeds. A linear module with the application of Hooke's law was used for static calculations. It was assumed that during operation (sowing) the supporting frame was affected by forces resulting from the loading of two containers with seeds weighing $500 \mathrm{~kg}$ each and by the resistance of 16 coulters on each of the coulter beams. A force of $200 \mathrm{~N}$ was exerted on each coulter vertically and horizontally (Fig. 2). The calculations allowed for the dead weight of the supporting frame of the innovative mechanical pneumatic seed drill and a safety coefficient of 1.6.

Due to the absence of permanent deformations in elements of the supporting structure, a linear-elastic characteristic of the material was assumed for simulation calculations. All supporting elements of the frame were made of steel with the following mechanical properties: Young's modulus $\mathrm{E}=210 \mathrm{GPa}$, Poisson number $v=0.3$ and density $\rho=7.860 \mathrm{~kg} / \mathrm{m}^{3}$. The yield point necessary to assess the effort of the supporting elements of the frame was $\mathrm{Re}=235 \mathrm{MPa}$.

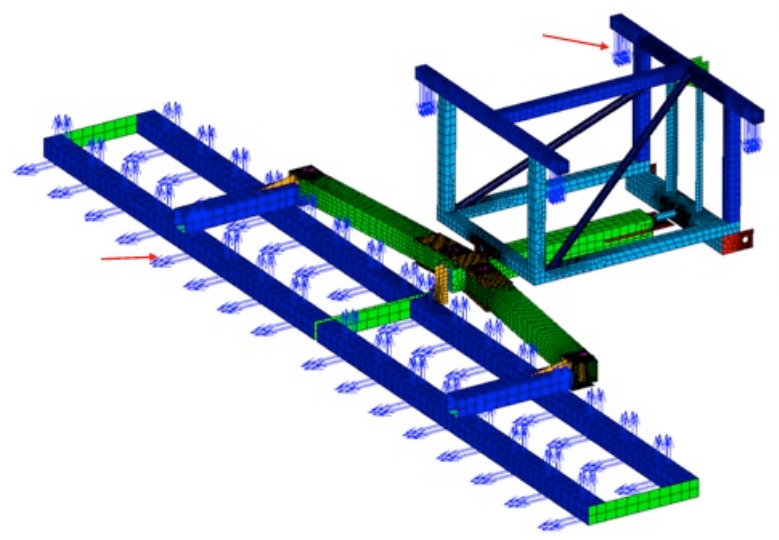

Fig. 2: Loads of the calculation model.

\section{Results}

Fig. 3 shows the results of reduced tensions, the displacement of nodes shown in fig. 4. The maximum value of tensions reduced in elements of the seed drill frame amounted to $\sigma \approx 211 \mathrm{MPa}$, allowing for the safety coefficient of 1.6. The beam in the area where the bolt fixing the frame arm was mounted was the element exposed to the greatest effort. The maximum tensions were not exceeded. However, if we consider cyclical load variation, it would be necessary to think about making changes to the construction and allow for the fatigue strength. The next stage of the research involved measurements of the maximum displacement of the model nodes at the ends of the left and right coulter frames. The maximum displacement value was $25.5 \mathrm{~mm}$.

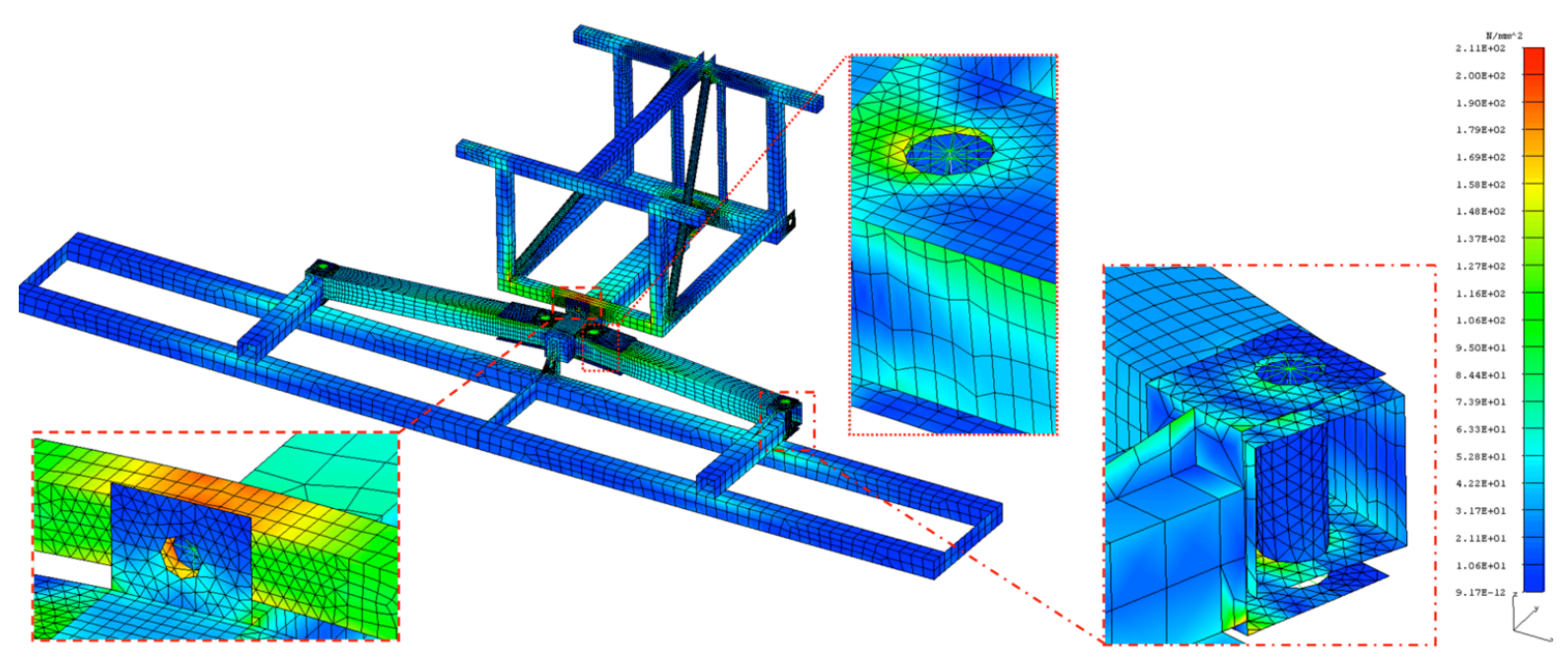

Fig. 3: A map of Huber-Mises tensions - detailed view of the bolt fixing. 

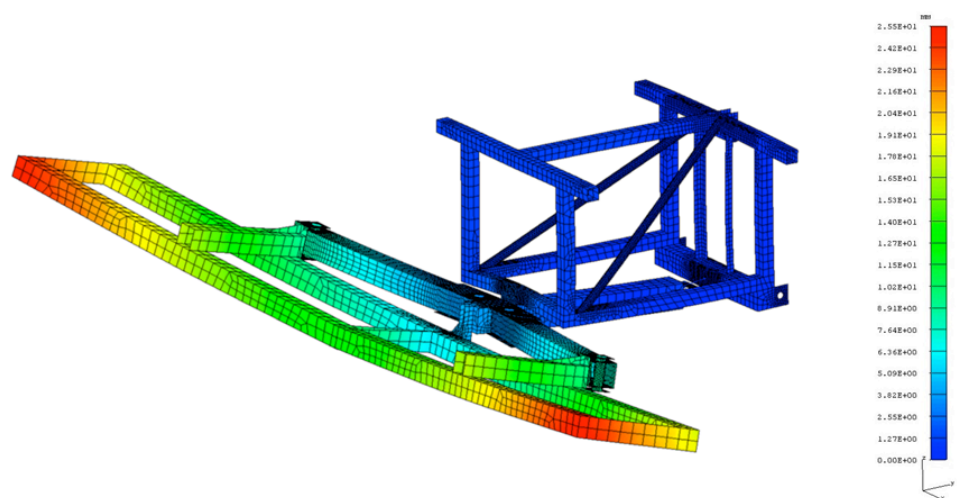

Fig. 4: Displacement of nodes in the net of the seed drill frame.

\section{Conclusions}

1. The finite element method used for analysis of one-dimensional, two-dimensional and gap finite elements enabled identification of the most exposed and stressed elements of the construction.

2. In the standard load variant during sowing the maximum permissible tensions were not exceeded either in the material or in the welded joints although the element of the frame with the arm bolt was the most stressed. These results confirmed earlier initial tests with one-dimensional elements.

3. The 3-D model reflected the actual conditions of the seed drill operation well. It enables modifications, e.g. optimization of the frame strength to reduce the weight of the construction and to save material, simultaneously maintaining the strength parameters.

4. In order to increase the credibility of theoretical calculations the results of the FEM calculations were verified empirically through measurements of actual frame deformations at selected points by means of tension measuring devices (Gierz, 2017).

5. The results of the analysis could be a significant factor in research on the development and optimization of new constructions of farming machinery, especially mechanical pneumatic seed drills.

\section{Acknowledgements}

The research was supported by statutory resources appropriated to Institute of Machines and Motor Vehicles, Poznań University of Technology No. 05/51/DSPB/3551.

\section{References}

Chodurski M, Dębski H, Samborski S, Teter A. (2015) Numerical strength analysis of the load-bearing frame of a palletizing robot's universal head. Eksploatacja i Niezawodnosc - Maintenance and Reliability; 17 (3): 374-378

Ferdynus M. (2013) An energy absorber in the form of a thin-walled column with square cross-section and dimples. Eksploatacja i Niezawodnosc - Maintenance and Reliability, 15 (3), s 253-258

Gierz Ł. (2017) Validation of FEM-based stress analysis of an innovative load-bearing structure of air-assisted seed drills with electronic seeding control. Engineering Mechanics 2017, Brno University of Technology, Brno, pp. 334-337.

Gierz Ł., Kęska W., Gierz Sz. (2014) Folding beam. PL 219776

Gierz Ł., Kęska W., Selech J., Zakrzewska G. (2013) The team to press the coulter on the ground. PL 216916

Marti P. (2013) Theory of structures. Fundamentals framed structures, plates and shells. Wilhelm Ernst \& Sohn, Verlag für Architektur und technische Wissenschaften GmbH \& Co. KG, Berlin, Germany

Rutkowski J., Szczepaniak J. (2005) Simulations and analysis of virtual computer models in application to series of types of agricultural rollers. J. of Research and Applications in Agricultural Eng., Vol. 50(1). S. 5-9 (in Polish)

Szczepaniak J., Pawłowski T. (2005) Modern methods of agricultural machine designing and verification. Agricultural Engineering, nr 14(74), s.267-275 (in Polish)

Zastempowski M., Bochat A. (2014) Modeling of cutting process by the shear-finger cutting block. ASABE Applied Engineering in Agriculture, Vol. 30, No. 3, pp. 347-353

Zastempowski M., Bochat A. (2015) Mathematical model ling of elastic deflection of a tubular cross-section. Polish Maritime Research No.2 (86), Vol. 22, pp. 93-100

Zienkiewicz O. C., Taylor R. L. (2005) The Finite Element Method for Solid And Structural Mechanics, Butterworth-Heineman. s. 440-450 